\title{
KENDALI OTOMATIS PENYIRAMAN URINOIR DENGAN SENSOR ULTRASONIK DAN ARDUINO UNO
}

\author{
Achmadi Prihantono ${ }^{1)}$ \\ ${ }^{1)}$ Fakultas Teknologi Informasi, Jurusan Sistem Komputer, Universitas Islam Balitar \\ Ahmadpri94@gmail.com ${ }^{1)}$
}

\begin{abstract}
Abstrak: Urinoir merupakan salah satu alat sanitasi yang berguna sebagai tempat buang air kecil (BAK) khususnya untuk kaum pria, yang mana limbahnya dapat langsung dialirkan ke selokan atau tempat penampungan. Urinoir otomatis merupakan pengembangan dari urinoir manual yang dirasa kurang praktis dan akan menambah minat masyarakat terutama para pria untuk tidak buang air kecil secara sembarangan. Urinoir otomatis bekerja ketika terdapat objek yang berada di depan sensor ultrasonik dengan jarak maksimal $30 \mathrm{~cm}$, dan ketika pengguna meninggalkan urinoir maka kran akan langsung menyiram secara otomatis selama 8 detik. Saat sensor ultrasonik mendeteksi adanya objek dengan jarak kurang dari $30 \mathrm{~cm}$ maka Arduino tidak akan langsung mengaktifkan relay dikarenakan relay akan aktif ketika objek berada lebih dari $30 \mathrm{~cm}$ dari jangkauan sensor, sehingga proses penyiraman akan lebih efisien dikarenakan tidak berpatokan dari seberapa lamanya objek berada di depan sensor.
\end{abstract}

Kata Kunci: Arduino, Sensor Ultrasonik, Relay, Urinoir.

Abstract: Urinal is one tool that is useful as a sanitary urination, especially for men in which waste can be directly channeled into sewers or shelter. Automatic urinal is the development of the manual urinal that is less practical and will add to the interest of the community, especially the men to not urinate indiscriminately. Automatic urinal works when there are objects that are in front of the ultrasonic sensor with a maximum distance of $30 \mathrm{~cm}$, and when the user leaves the urinal flush valves automatically will direct for 8 seconds. When the ultrasonic sensor detects the presence of an object at a distance of less than $30 \mathrm{~cm}$ then Arduino will not immediately activate the relay because relay will be active when the object is more than $30 \mathrm{~cm}$ from the sensor range.

Keyword: Arduino, Ultrasonic Sensor, Relay, Urinal.

\section{PENDAhUluan}

$\mathrm{S}$ emakin berkembangnya teknologi membuat berbagai macam sistem otomatisasi pada berbagai alat juga mengalami kemajuan, salah satu contohya adalah otomatisasi yang terdapat pada alat bantu manusia yang terdapat dalam bidang elektronika. Dengan terdapatnya sistem otomatisasi diharapkan dapat meringankan pekerjaan manusia.

Selain dalam bidang elektronika, sistem otomatisasi juga sudah diterapkan dalam bidang sanitasi dalam hal ini alat yang dimaksud adalah urinoir, [1]urinoir merupakan tempat buang air kecil khususnya laki-laki, limbahnya dialirkan langsung ke selokan atau tempat penampungan. Pada awal kemunculan urinoir dibuat tanpa adanya sistem penyiraman secara otomatis, hal tersebut dirasa kurang higenis dikarenakan keran air yang sama digunakan oleh banyak orang secara bergantian, saat sekarang ini banyak toilet umum yang menggunakan urinoir seperti yang terdapat pada rumah sakit, restoran, tempat ibadah, mall, dll. Dengan perkembangan teknologi maka urinoir mulai dikembangkan dengan sistem penyiraman otomatis. Sebelumnya mahasiswa Politeknik Negeri Padang bernama Indriyanto Romadeni 
pada tahun 2013 mengangkat judul tugas akhir "Sistem Kendali Keran Otomatis Pada Urinoir(Toilet Pria) dengan Sensor Gas Amonia", dimana prinsip kerjanya adalah sensor gas akan mendeteksi adanya polutan gas amonia pada urine dan hasil dari pembacaan sensor akan ditampilkan pada LCD.

Pada prinsipnya urinoir otomatis dikontrol oleh mikrokontroler yang terdapat pada board Arduino, [2] Arduino merupakan sebuah platform prototype dari physical computing yang bersifat open source hardware yang berdasarkan pada perangkat keras dan perangkat dan perangkat lunak yang mudah digunakan. Berdasarkan jabaran diatas, penulis mengangkat judul jurnal "Kendali Otomatis Penyiraman Urinoir dengan Sensor Ultrasonik dan Arduino Uno" dengan memanfaatkan sensor ultrasonik yang akan mendeteksi ada atau tidaknya pengguna yang berada pada jarak tertentu didepan urinoir tersebut, [3]sensor ultrasonik merupakan sensor yang berfungsi untuk mengubah besaran fisis menjadi besaran listrik dan sebaliknya, cara kerja sensor ini didasarkan pada prinsip dari pantulan suatu gelombang suara sehingga dapat dipakai untuk menafsirkan eksistensi(jarak) suatu benda dengan frekuensi tertentu. Arduino digunakan untuk menyimpan berbagai macam program yang dibutuhkan agar dapat menjalankan fungsi sensor ultrasonik sesuai yang sudah direncanakan. Perbedaan penelitian ini dengan penelitian sebelumnya terdapat pada sensor yang digunakan, dimana pada penelitian kali ini menggunakan sensor ultrasonik sebagai pendeteksi ada atau tidaknya pengguna yang berada didepan urinoir dan akan berfungsi sebagai pengirim perintah untuk mengaktifkan relay dan pompa air.

\section{Metode Penelitian}

Penelitian ini dilakukan selama 2 bulan terhitung dari bulan Juni hingga bulan Agustus 2018 bertempat di kampus Universitas Islam Balitar, adapun penelitian ini menggunakan penelitian jenis $\mathrm{RnD}$, [4] $\mathrm{RnD}$ merupakan jenis penelitian "need to do" yang hasilnya digunakan untuk membantu pelaksanaan pekerjaan.

\section{A. Desain Alat}

Pada bagian ini merupakan tahapan proses dimana perencanaan alat dalam bentuk gambar yang bertujuan untuk meminimalisir terjadinya kesalahan dan alat dapat berjalan sesua rencana. Adapun desain alat sebagai berikut. 


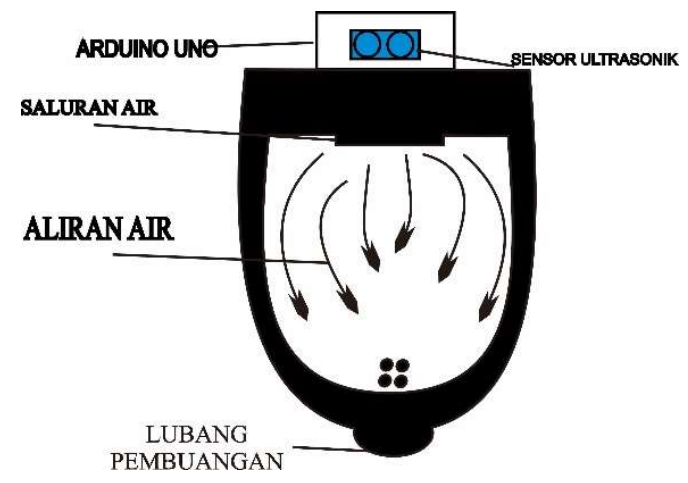

Gambar 1 Desain Alat tampak Depan

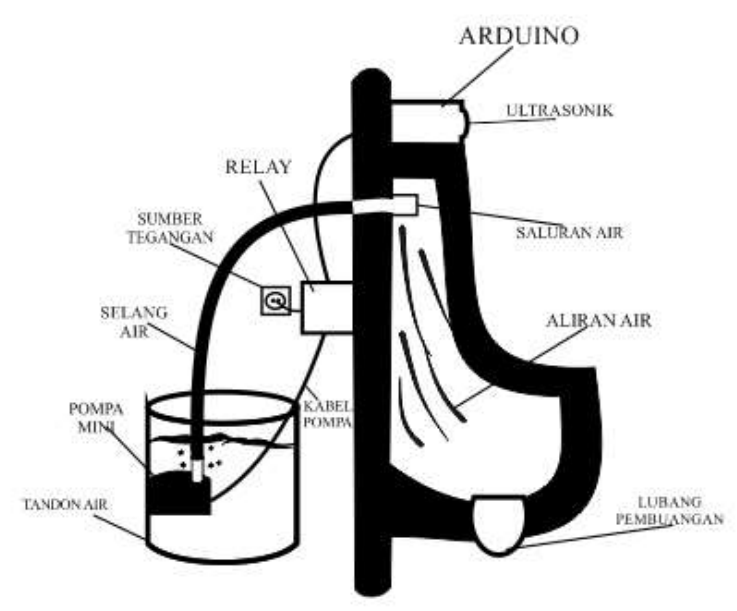

Gambar 2 Desain Alat Tampak Samping

Berikut merupakan komponen-komponen yang dibutuhkan untuk mendukung berjalannya alat agar berfungsi dengan baik. Komponen yang digunakan dapat dilihat pada tabel di bawah.

Tabel 1 Daftar komponen

\begin{tabular}{|l|l|l|}
\hline No. & $\begin{array}{l}\text { Nama } \\
\text { komponen }\end{array}$ & Jumlah \\
\hline 1 & Arduino UNO R3 & 1 \\
\hline 2 & Relay & 1 \\
\hline 3 & Pompa Air DC & 1 \\
\hline 4 & Sensor Ultrasonik & 1 \\
\hline 5 & Jerigen & 1 \\
\hline 6 & Kabel Jumper & Secukupnya \\
\hline 7 & $\begin{array}{l}\text { Board PCB } \\
\text { Matrik }\end{array}$ & \\
\hline
\end{tabular}




\section{A. Blok Diagram Sistem}

Sebelum melakukan perancangan sistem terlebih dahulu dibuat blok diagram sebagai langkah awal pembuatan sistem. Blok diagram menggambarkan secara umum bagaimana cara kerja rangkaian secara keseluruhan. Tahapan kerja yang akan dilakukan dalam rencana penelitian ini dapat dilihat pada gambar 3.

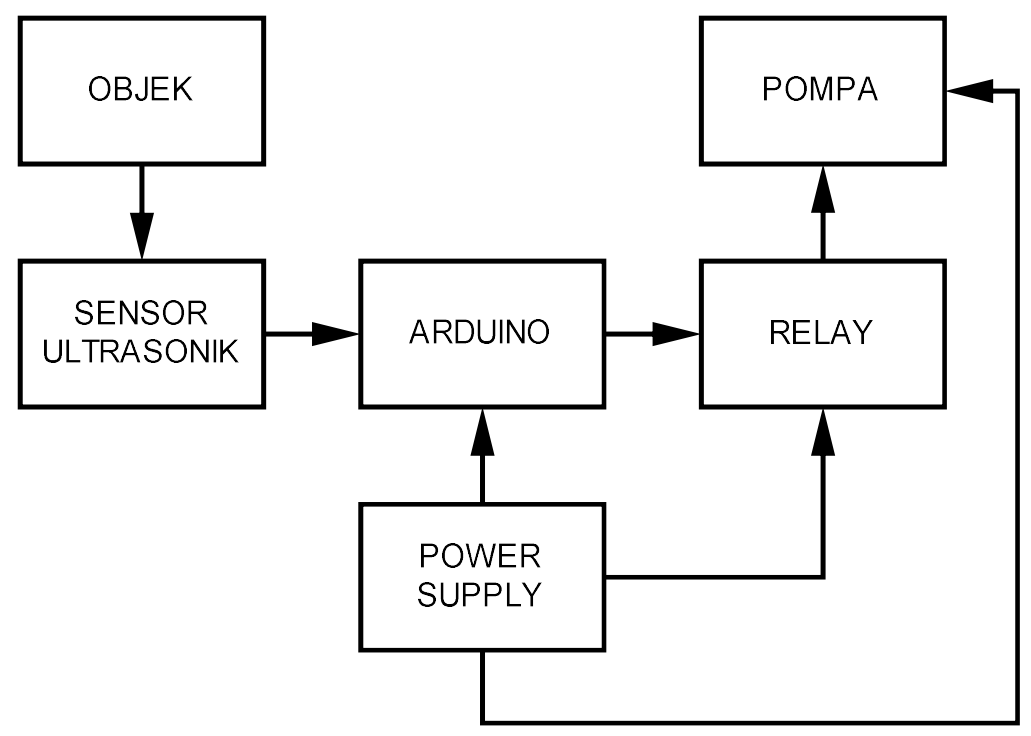

Gambar 3 Diagram Blok Sistem

Fungsi dari tiap-tiap blok sebagai berikut.

Power supply yang akan digunakan adalah tegangan DC sebesar 12V, dikarenakan tegangan tersebut adalah tegangan yang dianjurkan untuk mengoperasikan arduino. Mikrokontroler yang digunakan adalah ATMega 328 yang sudah tertananm pada board Arduino uno yang akan digunakan sebagai pusat kendali alat. Sensor ultrasonik berfungsi untuk mendeteksi ada atau tidaknya objek yang menghalangi. Relay berfungsi untuk menyalakan pompa setelah mendapat tegangan input dari Arduino uno.

\section{Pengujian Alat dan Hasil Pengujian}

\section{A. Pengujian Alat}

Pada pengujian alat bertujuan untuk mengetahui apakah alat dapat berjalan sesuai yang sudah direncanakan.

1. Pengujian Arduino

Pengujian pada Arduino dilakukan untuk mengetahui setiap pin yang terdapat pada Arduino dalam keadaan normal, salah satu caranya dengan menggunakan lampu LED yang ditancapkan pada salah satu pin Arduino.

2. Pengujian Relay 
Pengujian relay bertujuan untuk memastikan relay dalam keadaan normal dan siap digunakan untuk menyalakan pompa secara otomatis, caranya dengan mendengarkan bunyi pada relay apabila relay dalam keadaan high atau bisa juga dengan memperhatikan lampu indikator yang terdapat pada relay.

3. Pengujian Sensor Ultrasonik

Pengujian Ultrasonik bertujuan untuk mengetahui seberapa akurat pengukuran jarak dengan menggunakan ultrasonik dengan pengukuran yang dilakukan secara manual dengan penggaris, hasil pengukuran dapat diihat pada tabel dibawah.

Tabel 2 Pengukuran Ultrasonik

\begin{tabular}{|l|l|l|}
\hline \multirow{2}{*}{ NO } & \multicolumn{2}{|l|}{ Jarak Benda } \\
\cline { 2 - 3 } & $\begin{array}{l}\text { Pengukuran } \\
\text { Manual }(\mathbf{c m})\end{array}$ & $\begin{array}{l}\text { Sensor Ultrasonik } \\
(\mathbf{c m})\end{array}$ \\
\hline 1 & 5 & 5 \\
\hline 2 & 10 & 10 \\
\hline 3 & 18 & 19 \\
\hline 4 & 20 & 21 \\
\hline 5 & 25 & 25 \\
\hline 6 & 35 & 35 \\
\hline 7 & 45 & 44 \\
\hline
\end{tabular}

Hasil perbandingan pengukuran menggunakan alat ukur standar dengan hasil pengukuran sensor ultrasonik didapatkan nilai keluaran yang tidak jauh berbeda antara hasil ukur standar dengan sensor ultrasonik.

\section{B. Hasil Pengujian}

Hasil pengujian ini dilakukan dengan menggunakan 5 orang responden, setiap orang dibekali timer untuk menghitung seberapa lama waktu buang air kecil (BAK), sehingga urinoir otomatis akan bekerja ketika objek sudah tidak ada didepan sensor ultrasonik. Hasil penelitian ini akan menguji apakah alat tetap berungsi dengan baik ketika digunakan secara bergantian atau performa alat akan menurun.

Setelah melakukan pengujian alat secara keseluruhan maka dapat di jabarkan berupa tabel sebagai berikut. 
Tabel 3 hasil performa alat dengan jeda 5 detik antara user

\begin{tabular}{|l|l|l|}
\hline Orang ke & $\begin{array}{l}\text { Waktu } \\
\text { BAK } \\
\text { (Detik) }\end{array}$ & Keterangan \\
\hline 1 & 35 & Dapat Berfungsi \\
\hline 2 & 37 & Dapat Berfungsi \\
\hline 3 & 35 & Dapat Berfungsi \\
\hline 4 & 40 & Dapat Berfungsi \\
\hline 5 & 37 & Dapat Berfungsi \\
\hline
\end{tabular}

Tabel 4 hasil performa alat dengan jeda 8 detik antara user

\begin{tabular}{|l|l|l|}
\hline Orang ke & $\begin{array}{l}\text { Waktu } \\
\text { BAK } \\
\text { (Detik) }\end{array}$ & Keterangan \\
\hline 1 & 35 & Dapat Berfungsi \\
\hline 2 & 37 & Dapat Berfungsi \\
\hline 3 & 35 & Dapat Berfungsi \\
\hline 4 & 40 & Dapat Berfungsi \\
\hline 5 & 37 & Dapat Berfungsi \\
\hline
\end{tabular}

Tabel 5 hasil performa alat dengan jeda 15 detik antara user

\begin{tabular}{|l|l|l|}
\hline Orang ke & $\begin{array}{l}\text { Waktu } \\
\text { BAK } \\
\text { (Detik) }\end{array}$ & Keterangan \\
\hline 1 & 35 & Dapat Berfungsi \\
\hline 2 & 37 & Dapat Berfungsi \\
\hline 3 & 35 & Dapat Berfungsi \\
\hline 4 & 40 & Dapat Berfungsi \\
\hline 5 & 37 & Dapat Berfungsi \\
\hline
\end{tabular}


Tabel hasil 6 performa alat dengan jeda 20 detik antara user

\begin{tabular}{|l|l|l|}
\hline $\begin{array}{l}\text { Orang } \\
\text { ke }\end{array}$ & $\begin{array}{l}\text { Waktu } \\
\text { BAK } \\
\text { (Detik) }\end{array}$ & Keterangan \\
\hline 1 & 35 & Dapat Berfungsi \\
\hline 2 & 37 & Dapat Berfungsi \\
\hline 3 & 35 & Dapat Berfungsi \\
\hline 4 & 40 & Dapat Berfungsi \\
\hline 5 & 37 & Dapat Berfungsi \\
\hline
\end{tabular}

Dari tabel diatas didapati hasil bahwa alat tetap berfungsi dengan baik walaupun digunakan secara bergantian dan dengan selang waktu yang berbeda. Cara kerja dari alat ini adalah ketika sensor ultrasonik mendeteksi apakah sebelumnya ada objek yang menghalangi atau tidak, ketika sensor ultrasonik mendeteksi adanya objek seketika sensor akan mengirim perintah ke Arduino untuk standby dikarenakan objek masih berada didepan sensor dan masih dalam jarak kurang dari $30 \mathrm{~cm}$, ketika objek sudah meninggalkan urinoir atau lebih dari jarak maksimal maka Arduino akan menyalakan relay dan mengaktifkan pompa untuk menyiram urinoir secara keseluruhan selama 8 detik.

\section{KESIMPULAN}

Setelah melakukan serangkaian tahap perancangan dan perakitan sistem, yang kemudian dilakukan penelitian dan pengujian maka didapati kesimpulan bahwa urinoir otomatis dapat bekerja setelah sensor ultrasonik mendeteksi adanya objek berupa manusia. Proses penyiraman dilakukan setelah objek meninggalkan urinoir dengan jarak lebih dari $30 \mathrm{~cm}$ dan penyiraman dilakukan selama 8 detik. Sehingga proses penyiraman akan lebih efektif dikarenakan tidak berpatokan dari waktu buang air kecil setiap orang yang tentunya berbeda-beda

\section{DAfTAR Pustaka}

[1] Cahyadi, D, 2013. Rancang Bangun Sistem Pengolahan Limbah Urin Untuk Penyiraman Urinoir Uji Regresi Hasil Pengukuran Volume Air Penyiram Pada Urinoir Penentu Input Error.

[2] Djunandi, F. 2011 Pengenalan Arduino: Jakarta. www.tokobuku.com

[3] Muklisin , Dkk. 2017. Pendeteksi Volume Tandon Air Secara Otomatis Menggunakan Sensor Ultrasonik Berbasis Arduino Uno R3. Fakultas Teknik, Universitas Islam Balitar.

[4] Sugiyono. 2016. Cara Mudah Menyusun Skripsi, Tesis, dan Disertasi(STD). Bandung:ALFABETA. 